Media, Culture \& Society

Reporting on domestic violence in the Irish media: an exploratory study of journalists' perceptions and practices

(C) The Author(s) 2019

Article reuse guidelines: sagepub.com/journals-permissions DOI: |0.||77/0 |634437|8823 |4| journals.sagepub.com/home/mcs

@SAGE

\title{
Pauline Cullen
}

National University of Ireland, Maynooth, Ireland

\section{Anne O'Brien}

National University of Ireland, Maynooth, Ireland

\section{Mary Corcoran}

National University of Ireland, Maynooth, Ireland

\begin{abstract}
Media representations of domestic violence continue to be problematic. Few studies engage with journalists to understand how and why problematic representations are produced and endure. This research addresses that gap by exploring the challenges to journalists of reporting domestic violence. The key findings are that sources, conventions, and institutional constraints all constitute challenges to accurate reporting. Journalists note that police sources tend to avoid defining domestic violence as such. Consequently, problematic sources such as bystanders and community commentators are used. In addition, a number of long-held conventions prevail, including a default construction of reporting only the 'facts of the situation'; avoiding using the term domestic violence; and referring to incidents as singular, exceptional, and unexpected, with no connection made to other similar stories or broader aspects of gendered violence. Editors also place greater scrutiny on journalists working on domestic violence stories because of potential legal repercussions regarding defamation and adherence to court reporting's strict guidelines. Finally, relationships with domestic violence advocates are important for journalists in accessing expertise to help frame better understandings of the
\end{abstract}

\section{Corresponding author:}

Anne O'Brien, Department of Media Studies, lontas Building, National University of Ireland, Maynooth, W23F2H6, Ireland.

Email: anne.obrien@nuim.ie 
complexities of the issue. Until these structural and cultural problems in reporting are changed, much of the current misframing of domestic violence will endure.

\section{Keywords}

conventions, domestic violence, institutional practices, Irish media, journalists, sources

\section{Introduction}

Media depictions of domestic and sexual violence are an important element in how the public understands those issues and how relevant agencies devise strategies to advocate for victims (Comas-d'Argemir, 2015). Research suggests that the media tend to offer their audiences simplistic, inadequate, and distorted representations of the extent and nature of violence against women (Carlyle et al., 2008; Gillespie et al., 2013). The focus of much research has centered on how domestic violence is represented in print and broadcast media (Nettleton, 2011; Lloyd and Ramon, 2016; Richards et al., 2014). Somewhat less attention is paid to the broader context including the institutional, cultural, and practical dimensions of media work as factors shaping coverage (but see Morgan and Simons, 2017; Simons and Morgan, 2018). In the context of a specific incident of familial homicide, problematic media coverage of gender violence and homicide in Ireland has been the subject of recent debate and controversy (McDonald, 2016). However, little research exists on journalists' own perspectives on their professionally socialized approach to coverage. This article aims to address this gap drawing on an exploratory study of journalistic understandings of, and reflections upon, their production of domestic violence stories in Ireland.

The Irish gender regime is best understood as Catholic, liberal, and familialist. Resistant forms of traditional gender norms and public policy are most evident in the low levels of state support for childcare, historically restrictive access to reproductive rights and low levels of female representation in decision-making in cultural, political, and economic contexts (Devitt, 2016). Although there is a lack of reliable data on domestic and sexual violence in Ireland (Central Statistics Office (CSO), 2017), European level analysis suggests a significant rate of violence against women and low levels of reporting and prosecution (Fundamental Rights Agency, 2014). ${ }^{1}$ Despite the introduction of legislation on Domestic Violence in 2018 aimed at establishing specific guidelines for prosecution and improving victim's experiences of trials, judicial and criminal justice responses to domestic violence and sexual assault remain inadequate (Safe Ireland, 2018)..$^{2}$

Ireland as a historically conservative gender regime may have distinctive legacies that reproduce traditional gender norms, however, economic and social change place media industries within global trends, suggesting this case has purchase for analysis of other contexts. These include highly concentrated media ownership including global media interests; poor levels of female representation in senior decision-making roles across media industries; and tensions between professional socialization including commitments to objectivity, legal constraints surrounding reportage of crime, and commercial forces 
shaping media representation (Corcoran, Cullen \& O’ Brien, 2017). Irish media are also indicative of an increasing attendance to gendered social issues on media platforms, albeit in ways that oftentimes construct gender inequality in sensationalized, narrow, or inaccurate ways. The role of the Irish criminal justice system as an authenticated source for journalists and the deficits in training and expertise around gender violence are also indicative of the limitations evident in other jurisdictions (Corcoran, Cullen \& O' Brien, 2017).

With regard to Irish media, few studies have explored the journalistic worldview in an Irish context, although this is beginning to change (O'Brien, 2017, 2018). Irish journalists' ideological and political preferences, professional values and practices were the subject of a national survey of daily news journalists conducted in the late 1990s (Corcoran, 2004). Irish journalists see the organizations they work for as inherently more conservative than they are themselves, note that not all groups in society receive equal coverage and representation, and more than two-thirds of Irish journalists placed themselves as left of center (Author removed, 2004). This was similar to findings in five other (Western) countries (Patterson and Donsbach, 1996).

In the Summer of 2017 and the Spring of 2018, we conducted 12 in-depth interviews with respondents (journalists and advocates) who detailed both explicit and implicit 'rules' shaping their work. This article examines the definitions journalists employ to describe incidents of domestic violence, their key concerns and reservations when reporting on the issue, and their views on how domestic violence reporting might be improved. The key findings include that many media professionals are cognizant of the limitations inherent in the coverage they provide. In particular, journalists' testimony drew attention to the role of specific factors including the nature of sources available to them, the frameworks they deem acceptable to make sense of the 'facts' of the event, the role of editorial input made by senior media decision-makers, and the dearth of supports or training available to journalists covering domestic violence. Before presenting our analysis, we first contextualize media representation of domestic violence.

\section{Media representation of domestic violence}

Research on media representations of domestic violence note that reportage frequently mirrors societal constructions and ambivalence about violence against women (Morgan and Politoff, 2012). Five common elements in domestic violence coverage include the omission of social context, sensationalism, misrepresentation, victim blaming, and the erasure of victim's voices (Sutherland et al., 2016). Sutherland et al. (2016) note that media reports tend to be event based and use 'episodic framing', which focuses primarily on individuals' (Naylor, 2001) discrete incidents or events with individual incidents of particular but unpredictable interest to journalists (Gekoski et al., 2012; Morgan, 2015). There is a tendency, therefore, to ignore the overarching social context in which violence against women occurs. For instance, intimate partner violence and familial homicide may be reported as a single incident of family tragedy or as arising from occasional deviations in an otherwise harmonious family system. The emphasis placed on the aberrant and individualized aspects of specific incidents inhibits analysis of domestic violence as a broader social problem (Ryan et al., 2006). 
The focus on the supposedly deviant nature of these actions also constructs domestic violence in ways that fail to highlight its roots in broader gender-based power imbalances. Fairburn and Dawson (2013: 148) argue that the failure to report intimate partner violence as a social problem can be linked to a societal acceptance of gender violence as a private matter, and as such, an issue inappropriate for public intervention. Domestic violence may go wholly unreported or may be only partially represented because journalists are circumscribed by the broader ideologies shaping media institutions that work to 'reflect, reinforce and legitimize viewpoints that privilege men over women' (McManus and Dorfman, 2005: 44). The stories that gain most traction in media are not those concerning the most common forms of violence perpetrated against women but rather those that focus on the most severe forms of physical violence (Sutherland et al., 2016). While certain facts may be included or emphasized, others are omitted (Grabe et al., 2001). Through the use of particular words, metaphors, images, and catchphrases, the media has a large part to play in 'reflecting, shaping and challenging public opinion on gender based violence' (Easteal et al., 2014: 104).

Misrepresentation may result when the media approach an 'uncomfortable' issue such as domestic violence cases by avoiding its prevalence, normalizing it, blaming the victim, and blaming the criminal justice system (Sutherland et al, 2016: 5; Taylor, 2009). Lloyd and Ramon (2016) note that blaming the victim was the most commonly occurring theme across their analysis of media reporting on cases of domestic violence. Similarly, analysis of the coverage of femicide suggests that victim blaming, dismissing the perpetrator, or directing attention to lesser causes such as 'caretaker stress' all distort the reality of such crimes (Gillespie et al., 2013). Misrepresentation also occurs when domestic violence is downgraded, relative to other violent crimes in news coverage. In the United States, for instance, domestic violence arrests constitute the vast bulk of emergency calls dealing with a violent incident, but it is misrepresented by being covered in media 'much less often and with less depth than other violence of similar gravity' (McManus and Dorfman, 2005: 43).

Victims of domestic violence are often blamed or held partially responsible for the crimes committed against them (Sutherland et al., 2016). Notably, attributing blame and assigning responsibility was generally not done overtly but was mediated through subtle gendered messages (Gillespie et al., 2013). Femicide reporting, in particular, used sources such as friends, family, police, and judges who have a tendency to blame the victim for not taking 'serious enough action' against her abuser (Richards et al., 2011: 189). Moreover, indirect forms of victim blaming were also evident when sources mentioned the use of drugs/alcohol or mental health issues by either the perpetrator or the victim. Worryingly, victim-blaming language in the US news is mobilized more in connection with cases of domestic violence than in any other violent crime (Lloyd and Ramon, 2016).

Finally, reporting of domestic violence relies to a much greater extent on those connected to law enforcement and the criminal justice system than on women's own stories or information provided by advocates, service providers, or researchers (Sutherland et al., 2016: 6-8). The resultant 'police frame' tends to see domestic violence as an individual incident rather than as a social problem and erases gender while marginalizing the victim's experience (Meyers, 1997). Critical assessments of such reporting have stressed 
the need for more effective partnerships to be cultivated between the media, law enforcement, and advocates to raise awareness of domestic violence as a social problem and to ensure the accurate transmission of information about domestic violence among journalists and consumers (Gillespie et al., 2013; Kirkland, 2013). Notably the accuracy of reporting in the media has a direct effect on whether or not the public will elicit a sympathetic response, which is central to increasing the support and responsiveness to prevention efforts and protective measures (Carlyle et al., 2014).

\section{Methodology}

This study examines the institutional, cultural, and practical problems that journalists face when representing domestic violence. The research is situated within an explicitly feminist media studies framework. At its core, it adopts a gendered production studies approach, which questions patriarchal power structures that are exercised through the practices, culture, and traditions that shape media content in gendered ways. Production studies has an affinity with feminism in its study of gendered power within the cultures of media production (Banks, 2018: 157). The adoption of a gendered and feminist lens in the examination of how domestic violence is not only represented but also produced in a patterned and systematic fashion is essential to support changes in the nature of problematic production practices and representations.

Media participants in this research were employed by national broadsheet and mainstream broadcasters. Neither the perspective of tabloid nor local journalists are included in the analysis. While generalizations cannot be made on the basis of a small-scale, interview-based, Irish study, the emphasis here is on providing insights into and under researched area of journalists' working experience of covering a specific, sensitive, and complex topic. Well-chosen case studies provide opportunities to produce important exemplars, generate practical context dependent knowledge, and have merit in their proximity to studied realities (Flyvbjerg, 2006). As such, the intention here is not to offer a comprehensive account of the complex factors that shape media practice. Rather, we illuminate the experiences of media practitioners as they navigate the explicit and implicit 'rules' governing representation of domestic violence in a specific national context that is increasingly integrated into a global system of media production and illustrative of wider dynamics shaping international media practices.

Data are derived from semi-structured interviews with a purposive snowball sample of 12 stakeholders - advocacy organization professionals and media professionals from radio, television, print, and online outlets aimed at understanding media reporting of domestic violence. Respondents were asked about the implicit 'rules' and explicit regulatory frameworks that structure how incidents of, and legal proceedings pertaining to, domestic violence and homicide are reported. Questions addressed the specific constraints that shape how they approach the issue, such as the availability of sources; the legal and ethical context or market logics of print and broadcast journalism; the tacit and professional knowledge that informs journalistic framing, such as the role of unconscious bias; and the changes journalists would like to see in the nature, style, and format of gender-based violence coverage. All interviews were audio recorded, transcribed, and anonymized. Confidentiality was assured, and any details that might reveal journalists' 
identities were changed. Four key issues emerged from the analysis as key factors that shape journalists' coverage of domestic violence: the sources available, the framing that is applied to the facts, the editorial input made by senior decision-makers, and the dearth of supports available to journalists. Each of these four factors presents specific opportunities or challenges to journalists in covering domestic violence stories.

\section{Sources}

While sources are key elements that establish the credibility, legitimacy, and power of journalists, they may be selected in ways that reinforce the social power of specific constituencies (Franklin and Carlson, 2010; Simons and Morgan, 2018). In the case of domestic and sexual violence, sources are embedded in specific gendered, classed and racial dynamics that have implications for whose version of events and whose voices are represented and validated. Sources for journalists are then much more than information sources and reflect the hierarchical dynamics of the newsroom and the broader culture. To cover domestic violence effectively, there is a need for clear and accurate information, which is not always forthcoming. Law enforcement sources play a pivotal role in such media coverage (Sutherland et al., 2016). Feminist analysis of media reporting of gender violence, however, are critical of an over-reliance on police as sources. Police sources rarely frame domestic and sexual violence as a social issue and rather defer to more individualized accounts (Wozniak and McCloskey, 2010).

The main gatekeepers of information at crime scenes in Ireland - the Gardaí (Irish police force) do not generally engage with journalists directly, compelling the latter to rely on sources that do not have access to the facts of the case, such as local religious groups, community actors, or sports organizations. Nevertheless, our respondents are clear that police sources constitute the optimal verifiable source, but they are slow to offer basic information, even to define a crime. As one journalist put it, 'I don't think the guards would ever describe an incident as murder-suicide. I think you'd get it off the record that it's a murder-suicide but not on the record'. Without an official police declaration of a crime of domestic violence, journalists do not label incidents as such. Key challenges for journalists thus include police force reticence and a lack of clarity on naming an incident as domestic violence and an overall reluctance to proactively provide information about suspected acts of domestic violence. For instance, in cases of familicide-suicide, the Irish police often upheld the convention of presenting the incident as a set of tragic events rather than a 'crime', particularly, in the first statements on the incident. As one reporter who covered a familicide-suicide observed, 'Certainly the first day, if your primary source is the Gardai then ... it's described as a tragedy, and that's a quote, then that's what's going to end up getting used in the press release ...'.

Formal press briefings tend to be held only if the Gardaí deem them useful for finding a perpetrator. Even then, information issues only in response to direct questions from journalists. The internal processes of the Garda Press Office are also seen by journalists as too inefficient to meet the needs of a 24/7 instantaneous news cycle. While in Australia, research indicates that police have evolved their practices on dealing with and providing information on domestic and sexual violence (Simons and Morgan, 2018), in Ireland, the 
police force is less developed in its understanding and practices of communicating about crimes involving sexual and domestic violence (National Women's Council of Ireland (NWCI), 2018). As one journalist commented, 'I often think they're not trained in the media as much as they should be'. The Gardaí have begun a process of organizational reform around provision of services and supports to victims of domestic violence (Department of Justice, 2016). However, this initiative is deemed to be largely underresourced and slow to affect significant change in practices (NWCI, 2018). While dependent on police sources, journalists suggest that police framing of the crime, reticence to offer information, internal organizational processes, and their distrust of the media more generally create specific obstacles for journalists to name crimes as forms of domestic violence. Overall journalists characterized engagement with the police force as operating in a contested way, ranging from antagonistic to periodic and partial co-operation. The difficulties in drawing on police sources lead journalists to seek alternative sources for information.

A key source for critical incident type stories typically includes ordinary people and publicly available representatives of the community (e.g. sports organizations, religious leaders, local politicians), none of whom may have any factual insights on the crime committed. Such sources are relied upon for the basic facts of the situation, to get access to insider details of the story and to have voices and visuals necessary to fill airtime or collate copy. As one respondent observes, these sources are far from ideal in terms of garnering an objective factual account of incidents of domestic violence: 'You'd talk to everybody and anybody I suppose that's involved in their community that they might have had a link to at some stage'. Canvassing views widely is often the only pragmatic means of attaining a source. In that context, the local clergy is often the key. Journalists acknowledge that Church sources are partial in that their Christian or 'non-judgmental' framing as a consoling device may downplay the bald facts of the case as well as (initially) the perpetrators' responsibility. However, religious spokespeople are justified by journalists because they may speak for the community when others are unwilling or unable to do so. As a journalist explained,

It offers kind of a go-between in these situations. You don't want to be approaching a family, but you need to find out the details of who they are, who's involved. You also need to try and get pictures for newspapers and television, but we wouldn't want to be approaching a family.

Aside from community representatives, journalists also often gave airtime directly to neighbors and bystanders who are on site and accessible, especially, in the initial aftermath of a breaking story. As one interviewee observed,

the immediate thing you do is you try and talk to anybody else within a whisper of the scene of the crime. Usually, that's the neighbors and they mostly will have quite predictable comments to make, like, oh that never happened here before.

Such sources are reproduced in media accounts as verifiable and factual rather than as the subjective views of neighbors or bystanders, adding 'human interest' to the story. As one interviewee noted, 'You've got to make a judgment call on whether those people 
should be used or not because at the end of the day, someone's dead'. Reliance on casual sources may have the unintended consequence of misrepresenting rather than illuminating the reality of domestic violence.

Journalists producing planned feature pieces rather than engaging in critical incident reporting rely to a greater extent on expert sources, who can provide contextual analysis to stories of domestic violence. However, journalists are also cognizant of the risk of expert-led stories becoming 'strategy heavy', therefore, potentially alienating non-expert audiences. While journalists acknowledge the importance of social policy and legislative contexts, their immediate priority is to produce media content that is first and foremost 'relatable' to their audiences. For that reason, journalists tend to 'humanize' stories by using sources that have direct, first-person experience of domestic violence. As one respondent noted, 'You need that one person that's going to say "When I go in my door in the evening, this is what he does to me", and that's what catches people'. In other words, there is an implicit requirement that stories feature a 'victim' of domestic violence. This is a point of contention between journalists and advocacy agencies because the latter see the emphasis on victims as potentially exploitative rather than necessary (Corcoran, Cullen \& O'Brien, 2017). Advocacy organizations are often the first port of call for the media in sourcing a first-person account. Journalists are aware that the media's imperative 'to show, don't tell' can be interpreted by advocacy organizations as invasive, voyeuristic, and unnecessary as well as potentially traumatic or risky for survivors. As one journalist observed,

I think a lot of the time the organizations don't think of it that way, that we need a case study to cover the story and then they wonder why it's not being spoken about more. They have to engage more with the media as to what they can offer us in order for us to cover these stories for them.

Generally, journalists deem themselves to have good relations with some advocacy organizations but also express frustration with the different logics and time frames with which advocates and services providers work. One responded observed that 'NGOs have started to appreciate how important, articulate, really-well founded information is, and to be able to give it quickly to journalists'. At other times, however, poor communication and low levels of trust between journalists and support services for victims of domestic violence complicated efforts to correct misrepresentations and produce informed and well-researched media accounts. The advocacy sector is also perceived as having variable standards in terms of the rigor of their research and the information they provide, including their capacity to provide expertise in a timely fashion given the requirements of the news cycle. Nonetheless, a journalist noted that while some advocacy groups are better than others, generally 'they were very useful if you needed to be in touch with an individual that has been a victim or something like that'. The quick-fire time line that characterizes media production sits uneasily with the organizational logics and pastoral orientation of support groups. Moreover, one interviewee noted that if there are 'turf wars' between different advocacy groups, their credibility overall is somewhat reduced. Research in other jurisdictions also suggests a lack of proactive engagement from advocacy organizations, due in part to mistrust of the media, different agendas at play, their 
inexperience, and poor levels of resources (Simons and Morgan, 2018). This leads to the under-utilization of experts in coverage or their deployment for content when formats are already decided upon (Sutherland et al., 2016).

Overall, sources are defined by journalists as a limiting factor in permitting them to name violence and/or homicide against women as domestic violence crimes. Where official sources are not forthcoming, journalists seek information from bystanders and community leaders. Subjective accounts are likely to skew the angle on the story away from domestic violence as a social problem and toward the presentation of the story in a way that risked the occlusion or misrepresentation of the victim. This was brought into sharp relief in the Hawe case, which occurred in August 2016. In the immediate aftermath of the murder of Clodagh Hawe and her three sons, Liam, Ryan, and Niall, by her husband and the children's father, mainstream media accounts omitted her from the 'tragic' story or completely overshadowed her death through an overwhelming, and at times sympathetic, emphasis on the perpetrator and his motives (McDonald, 2016). The occlusion of the victim, such as occurred in the Hawe case, may be explained by the use of institutionalized frames, which journalists tend to apply to domestic violence stories.

\section{Framing}

Media frames can be understood as 'persistent patterns of selection, emphasis and exclusion that furnish a coherent interpretation and evaluation of events' (Norris et al., 2003: 2). Frames present one meaning out of multiple possible meanings, while simplifying, organizing, and structuring narratives, which, when repeated over time become the conventional way to define incidents in the media. Once established in media routines, frames are institutionalized through training, production practices, and 'news cultures which strengthen a common interpretation of events' (Norris et al, 2003: 8). We examine the process of constructing frames around domestic violence below. Respondents note that the framing of domestic violence changes subtly with the timeframe requirements of a given medium, be it television, print, or online output. Framing can be more reflective and contextual if a journalist is working in a features-based, magazine-style current affairs program rather than a rolling broadcast news bulletin.

There are a number of institutionalized conventions, explicit and implicit, that journalists bring to bear when they produce a story that is about domestic violence. These include focusing on the 'facts of the situation' only; not naming incidents as domestic violence because of prevailing legal restrictions; framing stories as single incidents rather than as sequences of pathological behavior; and reframing domestic violence stories by headlining the key issue as one of mental health or suicide. Some journalists noted the pressure emanating from audiences to frame domestic violence 'fairly' as something that equally affects men, despite the lack of statistical evidence supporting this assumption (Women's Aid, 2018). We outline the rationale that journalists offer to explain or justify each of these frames below.

Journalists frame incidents in terms of the 'facts only' and justify this in the context of the evolution of the story that is embedded in news genre conventions. In other words, as a story unfolds, each stage follows a particular journalistic convention. As one respondent observes, 'these things are very formulaic when it happens'. The first stage 
of reporting a critical incidence requires the presentation of facts without analysis: 'I think every story, definitely on the day it happens, is treated as an isolated incident, and it's very much the facts of that event that day'. Only on subsequent days might the story be re-framed in terms of other stories of a similar type. As a reporter points out,

In a follow-up, like the day after, usually in a story like that you'd still be at the scene the day after or even two days after, then it might be a case of linking it [to national statistics on domestic violence].

The factual focus, however, can lead to overlooking the role of domestic violence in the incident, at least in the short term. Respondents report that even more explicit and formal rules, which are institutionalized in abuse coverage, require critical incidents to be named as spouse attacks and murders rather than as domestic violence. One journalist who covered a domestic familicide and suicide commented on the inability to see the event through a different lens: 'I could never have made that leap, or no reporter could have made that leap in those immediate days'. There is a reluctance among journalists and their editors to name or frame a crime as domestic violence, unless the Gardaí specifically confirm the crime as such from the outset.

Some respondents recognize that failing to use the frame of domestic violence 'Hinders coverage and awareness of domestic violence, because people don't always connect the dots between abuse, domestic violence and murder'. They note the impact of implicit socio-cultural conventions such as observing sensitivity toward the victims, toward other potential victims, and toward the audience in general. One respondent comments, 'A lot of it is this Irish thing that well now everybody's dead, so let's let them rest in peace. That's a huge part of it - don't speak ill of the dead'. Another respondent notes that 'We have a way of life where we don't judge people that quickly, be it religion or whatever else ...'. These conventions are problematic because they rely on implicit rules that serve to misrepresent or obfuscate the social reality of the situation and leave key elements of the narrative unexplained for the wider audience.

A related framing convention in the coverage of domestic violence is either the absence of relevant helplines or the inclusion of inappropriate information in media stories. For instance, in the case of domestic murders, editors do not systematically direct audiences to appropriately framed helplines that pertain to domestic violence. More commonly, helplines relate to mental health and suicide prevention. This convention moves the focus or framing of the storyline away from domestic violence, subsuming it within another social problem, which may (depending on the specific aspects of the case) or may not be relevant. This misframing occurs because editors tend to respond to any agency that is proactive about supplying a helpline: 'When incidents like this happen, there are always a couple of emails that would come in from different organizations saying just be aware of the code of practice involved, and how its reported'. Advocacy agencies for victims of domestic violence are less proactive than more established group such as The Samaritans. Some respondents lack awareness of how the use of a mental health helpline instead of a domestic abuse helpline in the context of, for instance, a familicide shapes how that story is framed and, ultimately, interpreted. 
A framing challenge for news producers is how to cover domestic violence in a way that is 'new' enough to meet news and current affairs genre requirements but which still fits within the general parameters of public understandings of the issue. Journalists are aware of commonsensical and stereotypical notions of what domestic violence is and whom it affects. To shift the frame outside of such stereotypes, to cover, for instance, very young victims of domestic violence may be met with resistance by editors. The latter may want a 'new' angle on the issue but not at the expense of generalizing or sensationalizing from anecdotal accounts. In any event, the Gardaí's role as a trustworthy, corroborating source for new sub-category trends within domestic violence, is deemed crucial to authenticating the story. The Gardaí are the main source for national statistics on incidents of reported domestic violence. But there is currently a serious problem for journalists wishing to collate reliable data on the issue, due to the CSO publicly voiced concerns over the Gardaí's methodology for recording and collating data (CSO, 2017). This mirrors a lack of data more generally on domestic violence. One journalist commented on the fact that there is

remarkably little research done on domestic violence in Ireland ... there is research to be done on the impact of protective court orders on behavior ... I know certainly in child protection, when people talk about the impact of domestic violence on children, they're usually drawing on international research, which is fairly consistent across a lot of jurisdictions.

Finally, some respondents noted that the demands for 'fairness and balance' in coverage sometimes leads to a 'What about the men?' response from the audience, ignoring the actual statistical breakdown by gender of cases of domestic violence. A journalist explained,

comments appended under our articles ... complaining about our coverage of domestic violence ... might say, 'Why don't you talk about domestic violence against men?' We'll get emails about it, our readers saying to us that we're not covering it in a fair and balanced way.

As noted above, the paucity of reliable national data on a range of factors across the domestic violence spectrum is a further frustration for journalists seeking to defend the accuracy of their accounts.

In summary, the framing of domestic violence in the Irish media follows a number of long-held conventions, both implicit and explicit. First, incidents are framed in terms of the 'only the facts of the situation' which militates against timely naming of domestic violence. Police reluctance to define the event as one of domestic violence further contributes to this problem. Second, stories are frequently framed as single incidents rather than as part of a wider pattern of gender violence that operates (visibly and invisibly) across society. Journalists rationalize this approach by claiming that it is not 'up to them' to provide thematic links across cases concerned with a particular social problem. Third, stories may be misframed through an unreflective approach to the use of helplines, which downplay the role of domestic violence as a key attribute of the story. Journalists rationalize this framing as the outcome of the responsiveness of advocacy agencies that proactively contact them with helpline information. Finally, there may be pressure from elements of the audience to frame stories of domestic violence as an issue that affects 
men in equal measure, even when statistically, this is patently not the case. Journalists are unsure of how much they can resist such demands given the dearth of research in the Irish context, and the question of the reliability of data in the public domain. The effects of framing are further reinforced by the editorial approach to domestic violence.

\section{Editorial}

There is a sense among journalists that editors are willing in principle to engage with NGOs to improve coverage of domestic violence stories, 'I think there's definitely an openness from an editorial point of view and from a producers point of view to covering these features'. However, domestic violence stories involve additional oversight by editors in the context of critical incidents and court reporting. In the case of critical incidents of domestic violence that end in murder and/or suicide, there is additional editorial scrutiny because as one journalist explained,

for something delicate like a murder-suicide, you would work quite closely with your producer, to make sure that they're happy with what you're saying, that you're being respectful of the people involved, and that you're treating it in a very sensitive manner, because there's so many people involved, and because of the knock-on effects it has.

There are fears about leaving the media organization open to accusations of defamation, and a sensitivity to restrictions on reporting of cases that are sub judice.

Moreover, editors are aware that undermining cases in process and/or 'getting the story wrong' would impact significantly on their credibility as a news outlet. According to a veteran of court reporting, the restrictions on the family law court reporting (a considerable proportion of which would involve domestic violence) are to assure the privacy of the individuals concerned and to de-sensationalize the reporting. These court proceedings could not be reported until relatively recently, when a 2013 act allowed the media to attend family law proceedings. Defamation laws in Ireland are also particularly strict in comparison with other jurisdictions, and media professionals have lobbied for a reform of what they perceive as an oppressive regime (Collins, 2016). A fear of potential defamation cases taken by alleged perpetrators or the prospect of a case against an alleged perpetrator collapsing then motivates increased editorial oversight.

Editors are also reluctant to cover specific stories of domestic violence unless there had been a legal conviction. As one reporter put it, 'They'd want to be confident that there's been a conviction as well, this has become much more of an issue ... which makes it a lot more difficult to get people to talk'. Reporters were reflective about the potential bias in thematic coverage of domestic violence, if only those stories that are prosecuted through the legal system and result in a conviction are ultimately covered. A reporter observes,

You're kind of perpetrating the stereotype by only interviewing the person who's way further down the line and has come through the other side. If you're always speaking to the person who did leave- you know, there are people who can't even imagine getting to that point - so there is certainly a spin on that, there's a positivity to it. 
Legal restrictions effectively exclude the stories of those who, for instance, withdraw from seeking a protection order for reasons of intimidation. Without convictions, contributors to broadcast media stories were filmed and presented anonymously, which journalists acknowledge might serve to stigmatize the contributor rather than the perpetrator. Despite these difficulties, respondents generally believed that news outlets were open to the idea of covering of domestic violence. As a reporter put it, 'So there's all the ifs, ands or buts around it, but if it's done the right way, definitely producers have no problem broadcasting a story like that'. In helping achieve a more positive outcome for reporting on domestic violence, journalists were clear that advocacy agencies had an important role to play.

\section{External supports for journalists}

The increase in precarious work routines among media workers fosters greater pressure on younger journalists to maintain their profiles and their currency in the hope of attaining coveted staff positions. This trend is underpinned by a strong gender dynamic. Young journalists, covering domestic and gender violence incidents, are particularly vulnerable in this context. They are at once subjected to the increasingly competitive logics of their professional field and are exposed to the trauma of frontline reportage of distressing incidents. In Ireland, there is a lack of professional training and structured supports available to journalists covering traumatic stories (Corcoran, Cullen \& O' Brien, 2017). Journalists describe the challenges associated with being on site covering a femicide or familicide story. One journalist recalls,

how difficult that scenario is, being in a community, asking questions that nobody wants to talk about, being sworn at and being told where to go. It's one of the hardest jobs you can do, going to a scene like that, and it can be one of your lowest days because you're made feel it by some people.

Many of the respondents were general news reporters rather than specialists dealing with crime and with no specific expertise in dealing with the complexities of domestic violence. Another journalist reflects on the impact of this in the context of the 'speeded-up' news cycle:

I don't believe there to be any training (on domestic violence). I have taken part in legal training and things like that with people (but not with domestic violence coverage) every media outlet puts people into stories that hopefully have the experience to do it ... but you do have a news outlet that's under pressure, and is sending them in a hurry and just wants maybe a tabloid headline, so I'm sure not everyone goes in responsibly.

Journalists who feel less than expert in dealing with domestic violence see the benefit of engaging with specialist organizations to inform the content of coverage. However, this relationship needs to be delicately balanced, so that journalists are not perceived as biased or partisan:

The media has to think about its relationship with the public ... as well as its relationship with the (advocacy) groups, and what could be perceived as following their agenda ... (but) definitely if the women's groups or the domestic violence aid groups are ready to react and to offer support, even a very limited amount, yes that would be helpful if they were proactive on that. 
While advocacy groups may in theory be well placed to provide such support, they already struggle to resource outreach to victims (Author removed, 2018). Finally, respondents alluded to the difficulties they experienced after covering critical incidents. They were clear that there was very little if any aftercare available to them through their employers or trade unions or through advocacy organizations on how to cope with the ongoing distress such reporting caused to them as individuals. In general, no formal processes are in place for following up with journalists who have been privy to highly traumatic events resulting in injury or death of victims.

\section{Conclusion}

While scholars have established that gender violence is often represented in problematic ways in both broadcast and print media, little research has been conducted on the factors that shape journalists perceptions and practices when producing stories on the issue. This research has addressed that gap detailing four key issues that shape the production of domestic violence narratives. First, journalists name police sources as essential to their understanding of the nature of an incident and as vital to allowing them to classify an event as domestic violence. Journalists suggest that police sources may be overly conservative, reticent, and inefficient in their communications. As a consequence, journalists tend to rely on tacit professional knowledge of alternative sources, including bystanders and community commentators to frame their stories. This can result in a partial account of the incident and an occlusion of the underpinning role of everyday gendered regimes of abuse and control. Second, a number of long-held conventions are used by journalists to frame stories. These include: a tendency to report only the 'facts of the situation'; and avoiding using the term domestic violence; referring to incidents as singular and exceptional or unexpected with no connection made to other similar stories or broader aspects of gendered inequalities. Other conventions, such as the inclusion of less relevant helplines at the expense of more relevant helplines, also move the focus away from domestic violence. Third, input from editors places greater scrutiny on journalists working on domestic violence stories, reinforcing the extra sensitivity they must exercise in relation to potential legal repercussions or getting the story wrong. This potentially produces a 'chilling effect', with reporters and editors covering only stories with clear court outcomes, which are 'safer' rather than pursuing more investigative, open-ended stories on gender violence regimes. Finally, journalists identified a dearth of support for them in dealing with the effects of covering potentially distressing incidents.

While the findings from this study are based on a small-scale Irish case study, they may be relevant beyond this case as Irish media maintains a trajectory toward global formats that suggest the four key dimensions that shape outcomes - sources, framing, editorial, and support - have applicability in other international contexts. Further research is required to examine if this is the case. The study's focus on production studies is important because it emphasizes the importance of looking for the logics and structures that create problematic representations rather than merely critiquing the nature of representation. By systematically examining the production of stories the research highlights precisely where interventions for change can occur and identifies 
key organizational players needed to advocate for action to generate change. The research is also important because it invites further extensive, more wide-ranging research on the question of media production and domestic violence. More extensive studies with greater numbers of participants and in different contexts could provide additional detail on the dynamics shaping sources, framing, and editorial processes. Such analysis could deepen our understanding of the role of the broader institutional and ideational context, including the criminal justice system, gender regime, and the political economy of media as factors shaping the production of domestic violence narratives. Case studies across more and various media platforms, program formats, and genres of content will also help to further scope and contextualize the additional challenges that media workers face in attempting to create fair and balanced coverage of domestic violence. Perhaps, such a feminist production studies engagement can ultimately yield improved coverage and a move away from sensationalism, decontextualisation, misrepresentation, blaming, and a dearth of women's voices in stories on domestic violence. If a shift in the culture of media representations of domestic violence can occur, there might be some hope that a more refined public understanding of the issue can be achieved, with consequences for improved public policy and strategy for engagements around this key social problem.

\section{Acknowlegement}

We acknowledge the research assistance of Aisling Kennedy.

\section{Funding}

The author(s) received no financial support for the research, authorship, and/or publication of this article.

\section{Notes}

1. A 2014 study by the European Union Fundamental Rights Agency (FRA) reported that $14 \%$ of women in Ireland have experienced physical violence by a partner since age of 15 years; $6 \%$ of Irish women have experienced sexual violence by a current or former partner; $31 \%$ of women have experienced psychological violence by a partner; and 12\% of Irish respondents had experienced stalking (including cyberstalking).

2. In 2017, 21,451 contacts were made with direct services for domestic violence (Women's Aid Impact Report, 2017). Data collection on gender violence including domestic violence, domestic homicide, and sexual assault is poor.

\section{References}

Banks M (2018) Production studies. Feminist Media Histories 4(2): 157-161.

Bullock C and Cubert J (2002) Coverage of domestic violence fatalaties by newspapers in Washington state. Journal of Interpersonal Violence 17(5): 475-499.

Carlyle KE, Babin EA, Orr C, et al. (2014) News coverage of intimate partner violence: impact on prosocial responses. Media Psychology 17(4): 451-471.

Carlyle KE, Chakroff JL and Slater MD (2008) Newspaper coverage of intimate partner violence: skewing representations of risk. Journal of Communication 58(1): 168-186. 
Central Statistics Office (2017) Press statement CSO recorded crime statistics 7th September, 2017. Available at: http:/www.cso.ie/en/csolatestnews/pressreleases/2017pressreleases/ pressstatementcsorecordedcrimestatistics7thseptember2017/ (accessed 9 November 2018).

Collins S (2016) Minister for Justice announces review of defamation law. Available at: https:// www.irishtimes.com/news/crime-and-law/minister-for-justice-announces-review-of-defamation-law-1.2851020 (accessed 10 October 2018).

Comas-d'Argemir D (2015) News of partner femicides: the shift from private issue to public problem. European Journal of Communication 30(2): 121-136.

Corcoran M (2004) The political preferences and value orientations of Irish journalists. Irish Journal of Sociology 13: 23-42.

Corcoran M, Cullen P and O' Brien A (2017) Consultative document on media reporting of gender-based violence in Ireland. Dublin: National Women's Council of Ireland.

Department of Justice (2016) Second national strategy on domestic, sexual and gender based violence. Available at: http://www.cosc.ie/en/COSC/Pages/WP08000096 (accessed 9 November 2018).

Devitt C (2016) Mothers or migrants? Labour supply policies in Ireland 1997-2007. Social Politics 23: 214-238.

Easteal P, Holland K and Judd K (2014) Enduring themes and silences in media portrayals of violence against women. Women's Studies International Forum 48: 103-113.

Fairburn J and Dawson M (2013) Canadian news coverage of intimate partner homicide: analyzing changes over time. Feminist Criminology 8(3): 147-176.

Flyvbjerg B (2006) Five misunderstandings about case-study research. Qualitative Inquiry 12(2): 219-245.

Franklin B and Carlson M ( 2010) Journalists, Sources, and Credibility: New Perspectives. New York: Routledge.

Fundamental Rights Agency (2014) Violence against Women: An EU-Wide Survey Report. Vienna: Fundamental Rights Agency.

Gekoski A, Gray JM and Adler J (2012) What makes a homicide news- worthy? UK national tabloid newspaper journalists tell all. British Journal of Criminology 52(6): 1212-1232.

Gillespie LK, Richards TN, Givens EM, et al. (2013) Framing deadly domestic violence: why the media's spin matters in newspaper coverage of femicide. Violence against Women 19(2): $222-245$.

Grabe ME, Zhou S and Barnett B (2001) Explicating sensationalism in television news: content and the bells and whistles of form. Journal of Broadcasting and Electronic Media 45(4): 635-655.

Kirkland G, Dwayne Smith M, Givens EM, et al. (2013) Framing deadly domestic violence: why the media's spin matters in newspaper coverage of femicide. Violence Against Women 19(2):1-24.

Lloyd M and Ramon S (2016) Smoke and mirrors: U.K. newspaper representations of intimate partner domestic violence. Violence against Women 23(1): 1-26.

McDonald H (2016) Reporting of man who killed his family too sympathetic, say women's groups. groups. Available at https:/www.theguardian.com/world/2016/sep/02/reporting-alan-hawe-murder-suicide-family-sympathetic-say-womens-groups-wife-children (accessed 9 January 2019)

McManus J and Dorfman L (2005) Functional truth or sexist distortion? Assessing a feministcritique of intimate violence reporting. Journalism 6(1): 43-65.

Meyers M (1997) News Coverage of Violence Against Women: Engendering Blame. Thousand Oaks: Sage Publications.

Morgan J and Plintoff P (2012) Victorian print media coverage of violence against women. Available at https://www.vichealth.vic.gov.au/media-and-resources/publications/victorian-printmedia-coverage-of-violenceagainst-women (accessed 9 January 2019). 
Morgan J and Simons M (2017) Changing media coverage of violence against women. Journalism Practice 12(9): 1165-1182.

National Women's Council of Ireland (2018) Submission to the Commission on the Future of Policing in Ireland. Available at: https:/www.nwci.ie/images/uploads/FINAL_NWCI_ Submission_Policing_Commission_-_Jan_2018.pdf (accessed 24 November 2018).

Naylor B (2001) Reporting violence in the British print media: gendered stories. The Howard Journal of Criminal Justice 40(2): 180-194.

Nettleton PH (2011) Domestic violence in men's and women's magazines: women are guilty of choosing the wrong men, men are not guilty of hitting women. Women's Studies in Communication 34(2): 139-160.

Norris P, Montague K and Just RMR (2003) Framing Terrorism: The News Media, the Government and the Public. New York and London: Routledge.

O' Brien A (2017) Feminine or feminist? Women's media Leadership. Feminist Media Studies 17(5): 835-850.

O' Brien A (2018) (Not) Getting the credit: Women, liminal subjectivity and resisting neoliberalism in documentary production. Media Culture \& Society 40(5): 675-688.

Patterson TE and Donsbach W (1996) News decisions: journalists as Partisan actors. Political Communication 13: 455-468.

Richards TN, Gillespie LK and Smith MD (2011) Exploring news coverage of femicide: does reporting the news add insult to injury? Feminist Criminology 6(3): 178-202.

Richards TN, Gillespie LK and Smith MD (2014) An examination of the media portrayal of femicide-suicides: an exploratory frame analysis. Feminist Criminology 9(1): 24-44.

Ryan C, Anastario M and DaCunha A (2006) Changing coverage of domestic violence murders: a longitudinal experiment in participatory communication. Journal of Interpersonal Violence 21(2): 209-228.

Safe Ireland (2018) Submission to the Commission on Policing in Ireland. Available at: https:// www.safeireland.ie/wp-content/uploads/SAFE-Ireland-Submission-on-the-Future-ofPolicing-in-Ireland-.pdf (accessed 6 April 2018).

Simons M and Morgan J (2018) Changing media coverage of violence against women. Journalism Studies 19(8): 1202-1217.

Sutherland G, McCormack A, Easteal P, et al. (2016) Guidelines for reporting on violence against women in the news media. Australian Journalism Review 38(1): 5-17.

Taylor R (2009) Slain and slandered: a content analysis of the portrayal of femicide in crime news. Homicide Studies 13(1): 21-49.

Women's Aid (2017) Against the odds. Available at https:/www.womensaid.ie/download/pdf/ womens_aid_impact_report_2017.pdf (accessed 9 January 2019).

Women's Aid (2018) Breaking the Pattern of Male Violence: Femicide Watch 2018 Republic of Ireland. Dublin: Women's Aid.

Wozniak JA and McCloskey KA (2010) Fact or fiction? Gender issues related to newspaper reports of intimate partner homicide. Violence against Women 16(8): 934-952. 